DOI: $10.22616 /$ REEP.2019.019

\title{
A University Course of Intercultural Communication: Fostering Students' Skills and Competence
}

\author{
Lilia Raitskaya ${ }^{1}$ Dr. Sc.; Elena Tikhonova ${ }^{2}$ Ph.D. \\ Moscow State Institute of International Relations (MGIMO University), Russia ${ }^{1}$; \\ Peoples' Friendship University of Russia (RUDN University), Russia ${ }^{2}$; \\ Moscow State University of Food Production, Russia ${ }^{2}$ \\ raitskaya.1.k@inno.mgimo.ru'; etihonova@gmail.com²
}

\begin{abstract}
Intercultural communication has become an important interdisciplinary field of study of late against the backdrop of internationalisation in all spheres of life in modern society. It is defined as interpersonal communication in intercultural settings and measured by intercultural communication competence (ICC) level. The latter has come to the fore in many professions actualized in international environments. ICC is a complex of multiple components covering personal attributes and skills. Experiences in intercultural communication, acquired knowledge and expertise lead to higher ICC levels. To establish algorithms of enhancing ICC in university courses of intercultural competence, the research aims to determine potential changes in students' perceptions, attitudes and behaviours in intercultural communication settings via studies and simulated communicative landscape. The research design includes two tools: (1) a questionnaire with a view of finding out students' perceptions relating to intercultural communication and its phenomena, and (2) an ICC level assessment technology, measuring ICC before and after taking such a course. Based on the above methodology, the authors found out the students' perceptions of intercultural communication, most popular features of an efficient intercultural communicator (communicative, tolerant, friendly, talkative, agreeable, sociable, positive, flexible, easygoing, sensitive), professions deeply rooted in intercultural communication (psychologists, social workers, and others). The assessment carried out to diagnose the ICC levels before and after a university course of intercultural communication proved that the course takers excelled at some of the components (especially at intercultural behavioural skills, cultural knowledge, and cultural sensibility) singled out within the assessment methodology. The assessments highlighted the positive effects of a university course of intercultural communication on fostering ICC. The research implies that its findings may be generalised and applied in any similar university course to efficiently foster students' ICC.
\end{abstract}

Keywords: intercultural communication, culture, university, higher education, language.

\section{Introduction}

With globalization in all spheres of life and internationalization of global business and world economy on the rise, the issues of intercultural communication and intercultural communication competence (ICC) have come to the fore. Intercultural communication has been studied as a separate field since the mid1980s. Informed by research within plentiful approaches and disciplines (communication studies, foreign language education, management studies, sociology, interpersonal communication studies, psychology, social sciences, behaviourist approach, interpretive approach, social science (functionalist) approach, critical approach), intercultural communication is a widening area of research.

Authors define intercultural communication as 'interactions among people from different cultures' (Koester, Lustig, 2015, 20); as 'the exchange of information between individuals who are unalike culturally' (Rogers, Steinfatt, 1999). Z. Hua (2014) sees intercultural communication as a broader concept as situation where people 'from different cultural backgrounds come into contact with each other'. A more general approach is supported by J. Jackson stating that intercultural communication 'refers to interpersonal communication between individuals or groups who are affiliated with different cultural groups and/or socialized in different cultural (and, in most cases, linguistic) environments' (Jackson, 2014, 44). Some researchers focus on monoculturality vs interculturality to approach intercultural communication, as in the statement that 'the ability to see the world from different points of view is fundamental to the process of becoming intercultural' (Rogers, Steinfatt, 1999, 2). Intercultural relationships benefit to personality development as they encourage people to acquire knowledge about the world, break stereotypes, and foster new skills (Martin, Nakayama, 2010, 383). 
In theory, competence is defined ranging from a personality trait and largely inherent ability to an acquired ability gained via socialisation. Anyway, today competence is never regarded 'as a stable characteristic or trait of a person' (Chen, 2017, 351). Moreover, approaches to intercultural communication in various disciplines mainly depend on their 'emphasizing communicative' competence (related to foreign language education)', or 'their focus on' competence in communication' (Hua, 2014, 156).

Intercultural competence arises out of 'a pressing need for better preparation for cross-cultural adjustment and intercultural relationship building' (Jackson, 2014, 28). Depending on the disciplinary approach, ICC is broken down into various components, important for efficient communication in intercultural settings. 'A better understanding of ICC in day-to-day interactions can be arrived at by exploring how the people who are involved in those interactions describe and understand ICC' (Arasaratnam, Doerfel, 2005, 143). $M$. Byram notes that the exchange of information is dependent upon understanding how what one says or writes will be perceived and interpreted in another cultural context (Byram, 1997, 3).

ICC and related terms (intercultural communicative competence, intercultural communication, transcultural communication competence, cross-cultural competence, global competence, intercultural interaction competence (Hua, 2014)) are subject to interpretation. Having a lot in common, they are conceptually focused on some aspects of the skills and knowledge. Motivation to interact with other cultures, openness, positive attitude to otherness, high ambiguity tolerance, adaptability and other components of efficient intercultural communication contribute to success in intercultural communication. M.C. Bateson notes that 'an encounter with other cultures can lead to openness only if you can suspend the assumption of superiority, not seeing new worlds to conquer, but new worlds to respect' (Bateson, 2007).

In some professions, ICC is a 'survival' or backbone basis. For sociologists, teachers, interpreters, managers and similar domains, intercultural communication competence is enhanced throughout professional lives and careers. At universities, still more attention is paid to ICC integration into curricula of bachelor and master programmes to educate professionals ready for efficient intercultural interaction. Though some authors suppose that research... 'regarding the concept of intercultural competence and its relevance for ... future profession is insufficient' (Kostikova et al., 2018, 919).

The present research is an attempt to find out more about perceptions of future economist, diplomats, sociologists, and journalists relating to the domain of intercultural communication.

The research aimed to find out changes in university students' perceptions of intercultural communication phenomena against the backdrop of acquired knowledge and enhanced ICC while studying a course of intercultural communication at university.

Thus, to attain the aim, the research questions included the following:

1) What are the students' perceptions of intercultural communication and related issues?

2) How much does a course of intercultural communication change the students' attitudes and stances in intercultural communication and foster their ICC?

\section{Methodology}

The research design encompassed two research tools: a questionnaire covering questions on perceptions and stances in intercultural communication, and an adapted intercultural competence assessment methodology (The INCA project..., 2004).

Duration of the research: two years.

The course entitled 'Intercultural Communication' was delivered to 2nd-year bachelor students for one term, with ten flipped learning technology lectures, six project-based seminars, and two complex tests (mid-term and final). Flipped learning technology encourages students' motivation and manages cognitive load (Abeysekera, 2015). The ten classes are defined as lectures where professors sum up every theme previously studied by students on their own. Under the flipped technology, recommended sources are to be thoroughly analysed, tasks are completed, gaps and problems are sorted out for further discussion at lectures. Seminars follow lectures to nurture practical skills. The former were developed via projects, cases, and communicative tasks (communicative situations with a number of objectives to be attained).

Stage 1 (preceding the course). The sampling was formed to encompass second-year bachelor students at two Russian universities (i.e. MGIMO University and RUDN University) who were supposed to study 
a course of intercultural communication. The objectives of the study were explained to the participants. The students filled in a questionnaire via Google forms. All answers were anonymous.

At the very beginning of the course, all the participants underwent an intercultural competence assessment, reflecting on the intercultural situations offered. Thus, the level of their competence was fixed as 'entry level', or 'before-course level'.

Stage 2 (following the course). The sampled students' intercultural competence levels were assessed again ('after-course level').

Participants. The number of participants at Stage 1 included 187 students; though only 143 filled in the questionnaire, pre-course and after-course assessments. The remaining 143 bachelor students formed the research sampling, with 59 male and 84 female participants aged from 18 to 20 years old. Professionally, the students represented international economics (61 students, or $42.6 \%$ ), history (24 students, or $16.8 \%$ ), journalism (19 students, $13.3 \%$ ), sociology (39 students, or $27.3 \%$ ). During a briefing with the prospective participants, they were informed of the aims of the research. Most participants expressed their professional interest in international communication and ICC. The students' explicit leaning towards the research subject led to a hypothesis that the participating bachelor students were probably skilled or at least aware of intercultural communication. The sampling took on students who voluntarily agreed to participate in the study.

Materials. The questionnaire was built up to cover questions relating to personal data (age, gender, majors, and previous experiences in intercultural communication), and questions to find out what the students knew about intercultural communication, and its phenomena at the beginning of the course. The questionnaire offered questions/ tasks requiring personal definitions or elaborate replies coupled with multiple choice questions on ICC-related phenomena and examples:

1. What is intercultural communication? (an open-end question)

2. Which are the most essential skills and personal traits for an efficient intercultural communicator? (a multiple-choice question)

3. Which professions are prone to intercultural contexts? (a multiple-choice question)

4. Which phenomena are studied within intercultural communication discipline field? (a multiplechoice question)

5. Describe a prominent communicator, proficient in intercultural communication. Give adjectives or simple sentences. (an open-end task)

\section{Tools for Assessing Intercultural and Global Competence}

The research design was initially based on Intercultural Competence Assessment Methodology worked out in 2004 within the EU INCA project. The project was funded by Leonardo da Vinci II and resulted in a suite of assessment tools (The INCA project..., 2004).

The concept behind the INCA breaks down the intercultural competence into six components to embrace ambiguity tolerance, behavioural flexibility, communicative awareness, knowledge discovery, respect for otherness, and empathy. The original methodology provided for three levels (basic; intermediate; full, or high) of the components development. All in all, the six components made up ICC. To assess the component level, and ultimately ICC itself, various situations simulating scenarios of intercultural nature were offered to the participants. Their responses to the situations were evaluated against a special scale of replies covering three levels attributed to each component in the assessment.

In the present research, the authors also outlined six components, but those representing both ICC-related knowledge- and skill-focused elements (Component 1: intercultural behavioural skills; Component 2: cultural knowledge; and Component 5: cultural sensibility) and elements relating to personal traits of communicators (Component 3: ambiguity tolerance; Component 4: behavioural flexibility; and Component 6: respect for otherness). The above selection of components was made up in a special theoretical study carried out by the authors within their course of intercultural communication.

The assessment situations and assessment scales also came from the same course. A number of communicative situations per each component level were selected from the didactic materials of the course to make up an assessment pool. Situations were picked up to match a specific aspect (i.e. ICC component). Six components with three levels each formed a pool of 720 situations (360 and 360 snapshots for entry level assessment and for after-course level assessment respectively). 


\section{Results and Discussion}

\section{Students' Perceptions of Intercultural Communication}

While taking up the survey, the participants put down various definitions of intercultural communication. In general, the latter may be boiled down to three broad concepts: (1) communication involving representatives of diverse cultures (49 answers, or 34.3 per cent); (2) communication among people with different mother tongues (44 answers, or 30.8 per cent); (3) communication or interaction pursued by people of different cultures determined by various language backgrounds (19 answers, or 13.3 per cent). The remaining 20 responses were of sporadic nature, quite vague and lied beyond the mainstream replies.

According to the questionnaire, the most essential skills and personal traits of an efficient intercultural communicator embrace social skills, interpersonal skills, flexibility, empathy, positivity, adaptability.

The participants brought out the professions that were most related to intercultural communication with psychologists and social workers as the frontrunners (118 and 101 respondents respectively), university lecturers (98 respondents), journalists (92 respondents), sociologists (89 respondents), interpreters (82 respondents), managers ( 77 respondents), lawyers ( 45 respondents), diplomats (42 respondents).

The students considered that the phenomena foremostly associated with intercultural communication included traditions, national stereotypes, cultures, languages, etiquette, schema behaviours.

They also highlighted the following adjectives (on average, each respondent indicated five adjectives) describing an efficient communicator (See Figure 1). Such a communicator must be communicative (96 respondents), tolerant ( 84 respondents), friendly ( 73 respondents), talkative (60 respondents), agreeable (59 respondents), sociable (55 respondents), positive (39 respondents), flexible (35 respondents), easygoing (33 respondents), sensitive (31 respondents), good-mannered (28 respondents), quick-witted (24 respondents), upbeat (22 respondents), optimistic (19 respondents), reasonable (12 respondents), openminded (11 respondents), and cheerful (11 respondents). The list is limited to adjectives repeated at least 10 times.

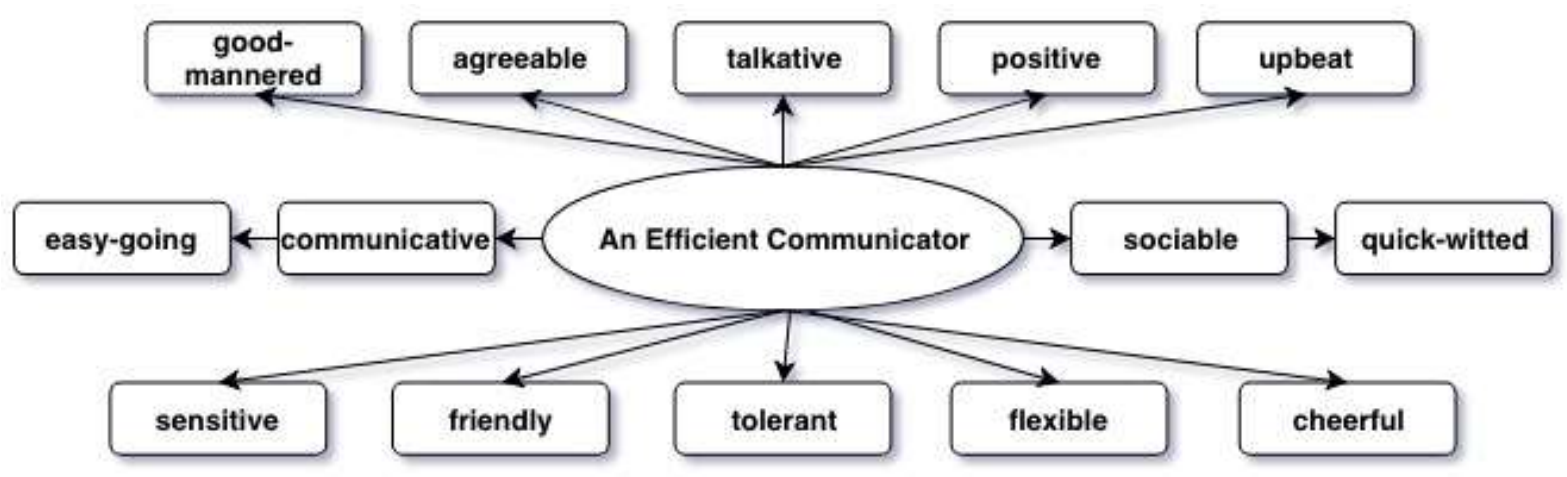

Figure 1. Frequent attributive adjectives typical of an efficient communicator as surveyed in the research.

The above findings connected with high efficiency in communication correlate with other studies. For instance, lecturers, whose job is to communicate knowledge and skills, are good at communication when they are friendly, positive, patient, attentive, and sociable (Mudra, 2018, 61).

The questionnaire responses proved that the respondents were aware of the basic notions of intercultural communication, most with previous experiences of going or studying abroad, or in environments where representatives of other cultures were involved. Entering universities, most students often have previous experiences in intercultural interactions (Tikhonova, Khorokhorina, 2014).

\section{ICC Assessments: before and after the course taken}

During the entry-level assessment, means for each component were calculated. Thus, the lowest mean indicator of 4.08 corresponded to intercultural behavioural skills, 4.15, 4.24 and 4.25 were calculated for cultural knowledge, ambiguity tolerance, and behavioural flexibility respectively. The highest readings 
of 4.27 and 4.29 were shown by cultural sensibility and respect for otherness. The mean for ICC entry level reached 4.21, thus, proving that the students' ICC was initially at an intermediate level.

As displayed on the graph (See Figure 2), all six after-course means considerably rose after the students had completed the course: intercultural behavioural skills at 5.04, cultural knowledge at 5.06, ambiguity tolerance at 4.76, behavioural flexibility at 4.98, cultural sensibility at 5.11 and respect for otherness at 5.05.

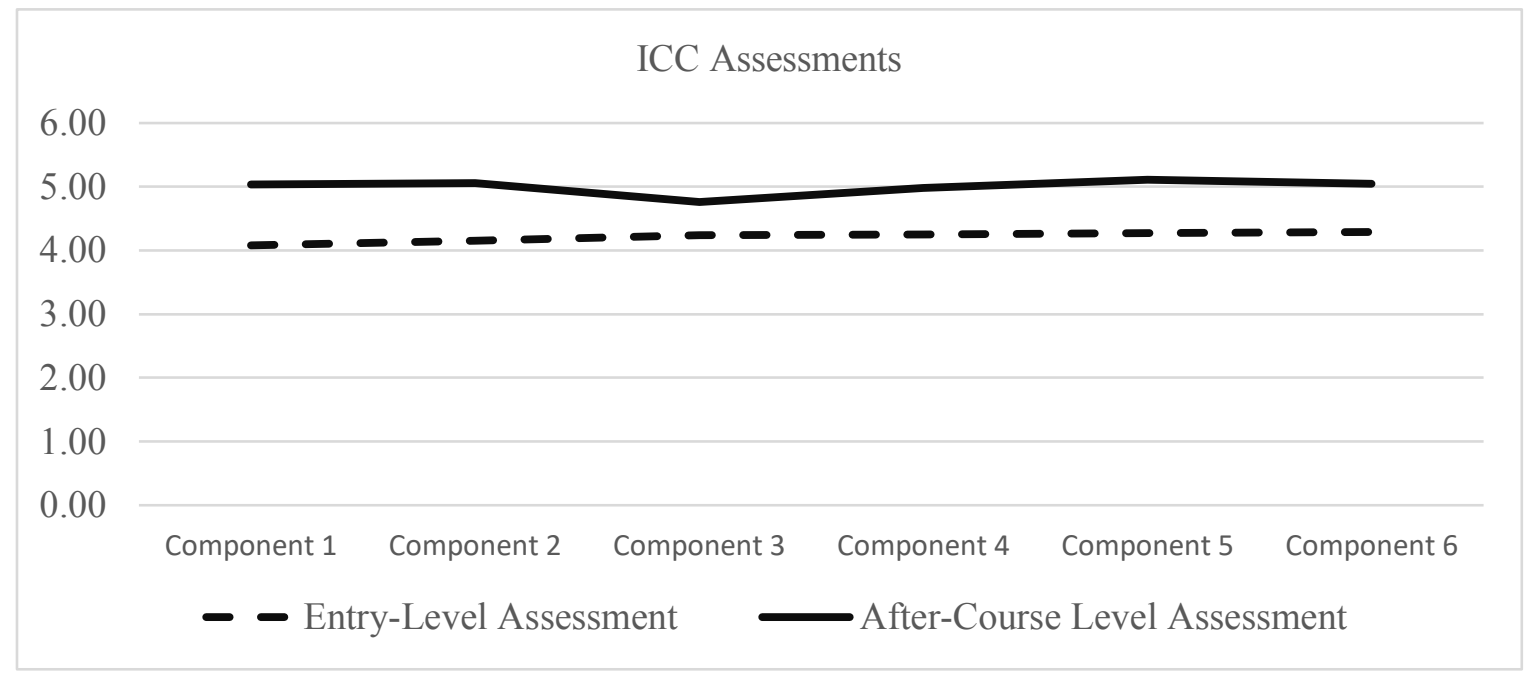

Figure 2. Entry-level and after-course level assessments of ICC (component means).

The highest surplus was made by intercultural behavioural skills (0.96), cultural knowledge (0.91), and cultural sensibility (0.84). The rise in those components is logically explained by the newly acquired knowledge and skills. These require less time and may be fostered in an artificially set up environment. In contrast, ambiguity tolerance, respect for otherness and behavioural flexibility cannot be easily influenced while studying. For instance, 'to have the ability to reduce uncertainty we need both to understand others, however different their cultural background may be from our own, and to be able to communicate with them sensitively' (McLaren, 1998, 5). It is evident that people need real-life experiences to succeed in building up ambiguity tolerance. The same is true for flexibility and attitude to otherness.

The data show that the delivered course boosted the students' ICC by 0.79 . The figure is extracted from the mean comparison of entry-level and after-course ICC level assessment results.

The research has a number of limitations. The sampling is confined to four professions. The assessments tests were simplified to cover only six components of the diversity of skills and attributes within the ICC. More separate studies may help to find algorithms to influence each component separately or in concert with others.

\section{Conclusions}

The research findings show that the students' perceptions of intercultural communication prove the hypothesis that they were aware and had some previous experiences before taking up the course of intercultural communication at university. The students perceive intercultural communication as communication among people of different cultural and/ or native language backgrounds. Social skills, interpersonal skills, flexibility, empathy, positivity, adaptability are singled out as the most essential skills and personal attributes for efficient intercultural communication. The top five professions closely related to intercultural communication cover psychologists, social workers, university lecturers, journalists, and sociologists. Traditions, national stereotypes, cultures, languages, etiquette, and schemas emerged from the questionnaire as well-known phenomena related to intercultural communication. The students find an efficient communicator communicative, tolerant, friendly, talkative, agreeable, sociable, positive, flexible, easy-going, sensitive (top 10 adjectives as attributes of an efficient communicator).

The research assessment methodology appeared to be efficient and reliable in measuring the ICC levels. The level assessments held before and after the university course of intercultural communication prove the course effect on enhancing the students' ICC, with the highest levels attained in such ICC components as intercultural behavioural skills, cultural knowledge, and cultural sensibility. The research 
also proves the hypothesis that the impact on skills is more evident that that on personal attributes. The findings imply that a course of intercultural communication taken by bachelor students leads to improvements in ICC, subject to deeper involvement in communicative situations and communicationsimulating settings.

\section{Bibliography}

1. Abeysekera L., Dawson P. (2015). Motivation and cognitive load in the flipped classroom: definition, rationale and a call for research. Higher Education Research \& Development, 34(1), 1-14.

2. Arasaratnam L.A., Doerfel M.L. (2005). Intercultural communication competence: Identifying key components from multicultural perspectives. International Journal of Intercultural relations, 29(2), 137-163.

3. Bateson M.C. (2007). Composing a life. New York: Grove Press.

4. Byram M. (1997). Teaching and assessing intercultural communicative competence. Clevedon: Multilingual matters.

5. Chen L. (ed.). (2017). Intercultural Communication. Boston/ Berlin: De Gruyter Mouton.

6. Hua Z. (2014). Exploring intercultural communication: Language in action. NY: Routledge, 2014.

7. The INCA project: Intercultural Competence Assessment. (2004). European Web Site on Integration. Retrieved from https://ec.europa.eu/migrant-integration/librarydoc/the-inca-projectintercultural-competence-assessment

8. Jackson J. (2014). Introducing language and intercultural communication. London and NY: Routledge.

9. Koester J., Lustig M.W. (2015). Intercultural communication competence: Theory, measurement, and application. International Journal of Intercultural relations, 48, 20-21.

10. Kostikova L.P., Prishvina V.V., Ilyushina A.V., Krutova I.Yu. Fedotova O.S. (2018). What does intercultural competence mean to university students? SGEM International Multidisciplinary Scientific Conference on Social Sciences and Arts. 5(3.,4), 919-926.

11. Martin J.N., Nakayama T.K. (Eds.). (2010). Intercultural communication in contexts. ( $1^{\text {st }}$ ed.). NY: McGraw Hill Higher Education.

12. McLaren M.C. (1998). Interpreting cultural differences: the challenge of intercultural communication. Norfolk, VA: Peter Francis Publishing.

13. Mudra H. (2018). A Study on the Attributes of Effective English Lecturers as Perceived by EFL Learners: The Case of Indonesia. Journal of Language and Education, 4(2), 59-67.

14. Rogers E.M., Steinfatt T.M. (1999). Intercultural Communication. Prospect Heights, ILL: Waveland Press.

15. Tikhonova E.V., Khorokhorina G.A. (2014). Cross-cultural communication in the mastery of foreign written language: individual and collective identification. International Conference of Education, Research and Innovation (ICERI), 7. Seville, Spain, 3657-3663. 